\title{
Biopolyols obtained via microwave-assisted liquefaction of lignin: structure, rheological, physical and thermal properties
}

\author{
Kamila Gosz $^{1} \cdot$ Paulina Kosmela $^{1}$ - Aleksander Hejna ${ }^{1} \cdot$ Grzegorz Gajowiec $^{2}$. \\ Łukasz Piszczyk ${ }^{1,3}$
}

Received: 25 July 2017 / Published online: 12 February 2018

(C) The Author(s) 2018. This article is an open access publication

\begin{abstract}
The present study examined the application of polyols obtained via microwave-assisted liquefaction of lignin in the production of rigid polyurethane foam. Lignin was liquefied in crude glycerol and 1,4-butanediol at different temperatures $\left(130-170{ }^{\circ} \mathrm{C}\right)$, without a catalyst and using various biomass concentrations (15 and $30 \mathrm{wt} \%$ ). The physicochemical properties, process yield, and FTIR-based identification of the obtained polyols were investigated. Under optimal conditions, i.e., a 5-min microwave heating time and a reaction temperature of $150{ }^{\circ} \mathrm{C}$, a polyol characterized by a suitable hydroxyl number of $670 \mathrm{mg} \mathrm{KOH} / \mathrm{g}$ was obtained with a 93\% process yield. Liquefied biopolyol was directly used for the production of rigid polyurethane foams with the addition of polymeric diphenylmethane diisocyanate at the $[\mathrm{NCO} / \mathrm{OH}]$ ratio of 2:1. Mechanical properties of the obtained foams gradually improved with increasing content of biopolyol. The $5 \%$ weight loss temperature $\left(T_{5}\right)$ for bio-based foams was higher, respectively 6 and $13{ }^{\circ} \mathrm{C}$ compared to the petrochemical foam. Replacement of petrochemical polyether with biopolyols showed the ability to obtain rigid polyurethane foams from lignin and crude glycerol.
\end{abstract}

Łukasz Piszczyk

lukpiszc@pg.gda.pl

1 Department of Polymer Technology, Chemical Faculty, Gdansk University of Technology, G.

Narutowicza Str. 11/12, 80-233 Gdańsk, Poland

2 Department of Materials Engineering and Bonding, Faculty of Mechanical Engineering, Gdansk University of Technology, G. Narutowicza Str. 11/12, 80-233 Gdańsk, Poland

3 Present Address: Department of Polymer Technology, Chemical Faculty, Gdansk University of Technology, G. Narutowicza Str. 11/12, 80-233 Gdańsk, Poland 


\section{Graphical Abstract}

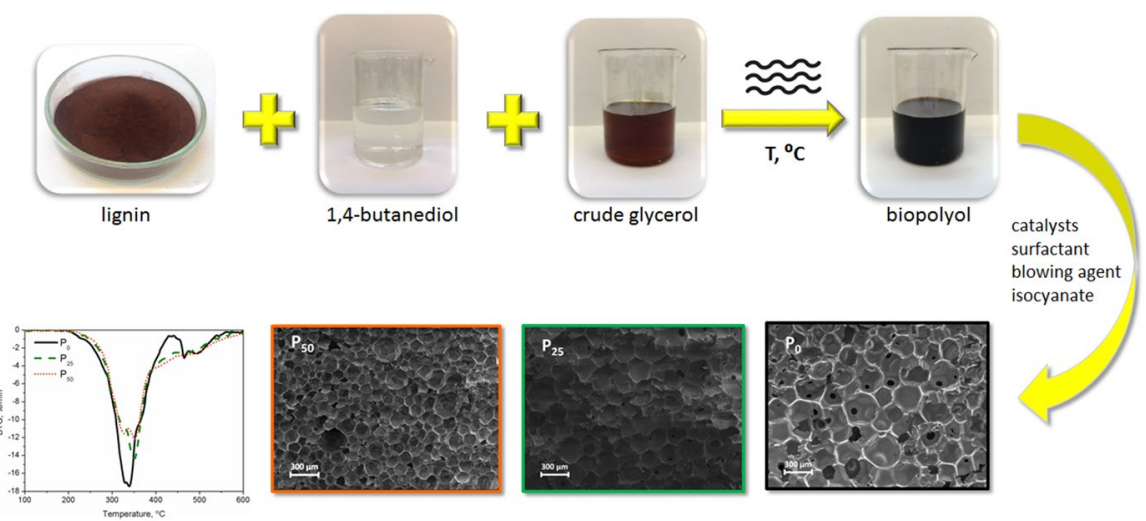

\section{Introduction}

Currently, utilization of lignocellulosic biomass attracts a lot of attention, mainly because of its counterparts, i.e., fossil fuels are causing various economic and ecological problems. Lignocellulosic biomass originating from waste wood (Yamada and Ono 1999; Kunaver et al. 2010) and agricultural crops (Lee et al. 2000; Liang et al. 2006; Wang and Chen 2007; Hassan et al. 2008; Yan et al. 2008, 2010; Chen and $\mathrm{Lu} 2009$; $\mathrm{Hu}$ and $\mathrm{Li} \mathrm{2014)} \mathrm{is} \mathrm{considered} \mathrm{to} \mathrm{be} \mathrm{the} \mathrm{most} \mathrm{abundant} \mathrm{renewable}$ raw material in the world. Lignocellulosic biomass consists mainly of cellulose (30-35\%), hemicellulose (15-35\%) and lignin (20-35\%) (Behrendt et al. 2008). It is rich in phenolic and aliphatic hydroxyl groups, as well as carboxyl groups possessing reactive hydrogen atoms, which make it a very promising material for the production of polyurethane materials. Lignin is a crucial component of plant cell walls, which is produced in the amount of $5 \times 10^{7}$ tons annually. It is a natural biopolymer with a three-dimensional network and a molecular weight of ca. 3000-7000 u. Lignin consists of units such as three types of monolignols ( $p$-coumaryl alcohol, coniferyl alcohol and sinapyl alcohol) that bind through radical coupling processes (Hatakeyama and Hatakeyama 2005). Aryl-ether bonds decompose more easily than the stable $\mathrm{C}-\mathrm{C}$ bonds, which are resistant to chemical depolymerization. Currently, the vast amount of lignin is generated as a by-product of the pulp and paper industry. In general, lignin is used as fuel, and only a small amount (1-2\%) is separated to be employed in industrial value-added applications (Gandini and Belgacem 2008; Kunaver et al. 2010). The obtained raw materials can be used in the production of polyurethanes, epoxy and phenolic resins (Yan et al. 2008; Gao et al. 2010; Hu and Li 2014), adhesives (Lee and Lin 2008) and foils (Kurimoto et al. 2000). To obtain a high-quality product, lignin has to be subjected to one of the following thermochemical conversions: direct combustion, pyrolysis, gasification or liquefaction. Various lignocellulose materials, such as wood (Kurimoto et al. 2000), paper (Lee et al. 
2002), straw (Wang and Chen 2007), bamboo (Yip et al. 2009), sugar cane (Abdel Hakim et al. 2011) and grain stalks (Wang et al. 2008), were liquefied by using different solvents to obtain polyols and subsequently produce polyurethane foams.

Liquefaction is a widely studied process that is based on depolymerization and dissolution of biomass at high temperatures. As a result, obtained products are enriched in hydroxyl groups. Conventional heating methods are relatively slow and inefficient due to low thermal conductivity in the entire volume. Initially, the surface of the material is heated and later, heat is transferred to the inside of the material. This means that there is a certain temperature gradient in the material. The application of microwave heating is an alternative way to achieve faster and homogeneous heating of the entire sample volume (de la Hoz et al. 2005). Microwave irradiation produces efficient internal heating by direct coupling of microwave energy with the molecules of solvents, reagents or catalysts. The observed effect of increasing the speed of chemical processes in the magnetic field is due to the thermal effect, i.e., the high process temperature obtained by the microwave radiation for polar materials increases their rate of chemical reaction in accordance with the Arrhenius law. During microwave heating, there are also specific thermal effects caused by accelerations of chemical transformations in the magnetic field that cannot be achieved or reproduced in conventional heating (de la Hoz et al. 2005; Mazo et al. 2012). Microwave heating has many advantages, for example, low energy use, very high heating rate and treatment time, lowered sintering temperature, improved physical and chemical properties, simplicity and lower risk for the environment. The attributes assigned to microwave heating have not been observed during heating with conventional methods (Clark et al. 2000; Yadoji et al. 2003; Agrawal 2006; Menezes et al. 2007; Leonelli et al. 2008).

Cinelli et al. (2013) prepared flexible polyurethane foams using microwaves to liquefy the lignin. At first, lignin was dried at $80{ }^{\circ} \mathrm{C}$ for $24 \mathrm{~h}$. The specified amounts of lignin, as well as glycerol and polyethylene glycol (PEG 400), which were used as solvents, were placed in glass flasks and subjected to microwave irradiation in a microwave oven $\left(180 \mathrm{~W}, 135^{\circ} \mathrm{C}, 3 \mathrm{~min}\right)$. The hydroxyl values of such prepared polyols varied from 645 to $661 \mathrm{mg} \mathrm{KOH} / \mathrm{g}$ depending on the ratio of substrates used. Next, the polyols were used to prepare flexible polyurethane foams that can be applied in furniture and automotive industries.

Xue et al. (2015) investigated preparation of polyols for rigid PU foams via liquefaction of lignin in mixture of glycerol and PEG 400. The reaction was catalyzed with sulfuric acid and performed through microwave-assisted liquefaction of microwave radiation at $140{ }^{\circ} \mathrm{C}$. Authors analyzed the impact of reaction time $(5,10$, 20, $30 \mathrm{~min}$ ) on the liquefaction yield, as well as chemical composition and structure of prepared materials. In optimal conditions, lignin was almost fully liquefied $(97.5 \%$ yield) and obtained polyol was characterized by the hydroxyl value of $863 \mathrm{mg} \mathrm{KOH} / \mathrm{g}$. The liquefied lignin products without pretreatments can be used in the preparation of rigid PU foams.

Sequeiros et al. (2013) investigated the influence of reaction time, temperature and catalyst concentration on the liquefaction process of lignin. To obtain a polyol with a high content of reactive hydroxyl groups, glycerol and PEG-400 were used as solvents. The reaction was catalyzed by sulfuric acid. After $5 \mathrm{~min}$ of a reaction 
conducted at $155{ }^{\circ} \mathrm{C}$ in the presence of $3 \%$ of catalyst, the reaction yield reached $99 \%$, while the resulting polyol had a hydroxyl number of $263 \mathrm{mg} \mathrm{KOH} / \mathrm{g}$. Decreasing the concentration of catalyst to $1 \%$ also led to reaction yield of $99 \%$, but the obtained polyol had much higher hydroxyl number, i.e., $811 \mathrm{mg} \mathrm{KOH} / \mathrm{g}$.

Presented literature data confirm that glycerol can be successfully applied as a liquefying agent to the manufacturing of polyols from various types of biomass. Therefore, other material, which should be considered as an interesting alternative solvent, is crude glycerol, generated as a by-product during production of biodiesel. It is estimated that ca. $1 \mathrm{~kg}$ of glycerol is generated per $10 \mathrm{~kg}$ of the produced diesel fuel. According to the statistical data, current annual biodiesel production exceeds $30 \mathrm{Mt}$, which results in the generation of $3 \mathrm{Mt}$ of waste glycerol that could be largely used in the production of plastics. In the case of biodiesel production, the composition of the post-reaction mixture is affected by factors such as technology, the type of raw material and catalyst, and the process parameters (Luo et al. 2013).

Crude glycerol has low economic value because it is contaminated with soaps, free fatty acids (FFA), fatty acid methyl esters (FAME) and glycerides (Hu et al. 2012a). The earlier studies indicate that crude glycerol can be used as an alternative solvent in the process of biomass liquefaction prior to the synthesis of polyols and PU foams ( $\mathrm{Hu}$ and $\mathrm{Li} \mathrm{2014).} \mathrm{Moreover,} \mathrm{the} \mathrm{published} \mathrm{results} \mathrm{also} \mathrm{demonstrate} \mathrm{that}$ some impurities present in crude glycerol actually improve liquefaction ( $\mathrm{Hu}$ and $\mathrm{Li}$ 2014). In general, the produced polyols and polyurethane foams display properties that are comparable to those of their analogs derived from crude oil (Lee et al. 2000; Alma et al. 2003; Chen and Lu 2009).

In this study, biopolyol was produced via microwave-assisted liquefaction of lignin using crude glycerol for the synthesis of biopolyol and bio-based rigid polyurethane foams. The three temperatures and two ratios of lignin to 1,4-butanediol to crude glycerol were used for the production of bio-based polyol. The obtained biopolyols were analyzed with respect to their physicochemical and thermal properties. Next, 25 and $50 \mathrm{wt} \%$ of petroleum-derived polyol was replaced by the novel biopolyol in the formulations of polyurethane foams. The morphology, mechanical and thermal properties of the bio-based foams were examined.

\section{Materials and methods}

Crude glycerol, obtained from Bio-Chem (Poland), contained approximately $96 \%$ glycerol, $2 \%$ total fatty acids, $1 \%$ methanol, $1 \%$ water, $0.06 \%$ salt and other impurities, and its density was $1.26 \mathrm{~g} / \mathrm{cm}^{3}$. 1,4-butanediol with a typical hydroxyl number of $1246 \mathrm{mg} \mathrm{KOH} / \mathrm{g}$ was purchased from POCH S.A. (Gliwice). The lignin used was provided by Sigma-Aldrich (Poland). It was Kraft pine lignin, free of hemicellulose, with a density of $1.3 \mathrm{~g} / \mathrm{cm}^{3}$.

The polyol used in this study was Rokopol RF551 (PCC Rokita SA, Poland), a general purpose sorbitol-based polyether polyol recommended for the production of rigid polyurethane foams. The density of Rokopol RF551 at $25{ }^{\circ} \mathrm{C}$ equaled $1.1 \mathrm{~g} /$ $\mathrm{cm}^{3}$, while its typical hydroxyl number $\left(\mathrm{L}_{\mathrm{OH}}\right)$ was $400-440 \mathrm{mg} \mathrm{KOH} / \mathrm{g}$ of resin and a viscosity at $25{ }^{\circ} \mathrm{C}$ equaled $5.8 \mathrm{~Pa}$ s. Its average molecular weight was $600 \mathrm{~g} / \mathrm{mol}$. 
Polymeric methylene diphenyl diisocyanate (pMDI) was supplied by Borsodchem (Hungary). The average functionality of pMDI was ca. 2.8, while the content of free isocyanate groups was 31.5\%. A $33 \mathrm{wt} \%$ solution of potassium acetate in ethylene glycol $\left(\mathrm{K}_{12}\right)$ was used as a gelling catalyst, while 2-[2-(dimethylamino)ethoxy] ethanol $\left(\mathrm{K}_{\mathrm{Amin}}\right)$ and tin 2-ethyl hexanoate $\left(\mathrm{Sn}(\mathrm{Oct})_{2}\right)$, applied as catalysts, were purchased from Sigma-Aldrich (Poland).

NIAX Silicone SR-393 (Momentive, Czech Republic) was used as a silicon-based surfactant. Carbon dioxide, generated in the reaction between water and isocyanate groups, was used as a chemical blowing agent. n-pentane (anhydrous, 99\%) from Chempur (Poland) served as a physical blowing agent. All chemicals were used as received.

\section{Liquefaction process of lignin}

Prior to the synthesis, lignin was dried for $24 \mathrm{~h}$ in an oven with air circulation at a temperature of $80{ }^{\circ} \mathrm{C}$. The liquefaction reactions were carried out in a Milestone microwave laboratory system equipped with $100-\mathrm{mL}$ sealed Teflon reaction vessels. Samples were irradiated for $5 \mathrm{~min}$ at the initial power level of $180 \mathrm{~W}$ (Cinelli et al. 2013). The reaction temperature was kept at 130,150 and $170{ }^{\circ} \mathrm{C}$. The ratios of lignin to 1,4-butanediol to crude glycerol were 0.5:0.5:2 $\left(\mathrm{L}_{0.5}\right)$ and 1:0.5:2 $\left(\mathrm{L}_{1}\right)$. After 5 min of liquefaction, the vessels were allowed to cool down to room temperature prior to opening.

\section{Preparation and characterization of PU foams}

Rigid polyurethane foams were obtained using the one-step method from the twocomponent system, with the $\mathrm{NCO} / \mathrm{OH}$ ratio of $2: 1$. Component A was obtained by thorough mixing (rotational speed of $1800 \mathrm{rpm}$, mixing time $60 \mathrm{~s}$ ) of the appropriate amounts of Rokopol RF551 and prepared biopolyol, catalysts, surfactants and blowing agents. Biopolyol was incorporated as a substitute of 25 and 50 parts by weight of oligoetherol used for producing the foam samples. Component B consisted of an isocyanate pMDI. Components $\mathrm{A}$ and $\mathrm{B}$ were mixed together at the selected mass ratio in the polypropylene cup. The obtained foams were heated in an oven at $60{ }^{\circ} \mathrm{C}$ for approx. $24 \mathrm{~h}$ and then cured at room temperature for $24 \mathrm{~h}$. Table 1 contains the details of the foam formulation.

\section{Characterization of liquefaction-derived polyols}

The hydroxyl value of the obtained polyol was determined in accordance with the standard PN-93/C-89052/03. Samples were dissolved in acetylation mixture and then heated in a steam bath. During heating, pyridine and distilled water were added. Titration with $0.5 \mathrm{M} \mathrm{KOH}$ in the presence of phenolphthalein was the next step. To properly determine the titration point in the dark brown liquid, the $\mathrm{pH}$ of the sample was measured at room temperature with a VOLTCRAFT pH-100 ATC pH meter. The hydroxyl value, defined as $\mathrm{mg} \mathrm{KOH} / \mathrm{g}$ of sample, was calculated as follows: 
Table 1 Formulation of PU foams

\begin{tabular}{|c|c|c|c|}
\hline \multirow{3}{*}{ Component } & \multicolumn{3}{|c|}{ Foam symbol } \\
\hline & $P_{0}$ & $P_{25}$ & $P_{50}$ \\
\hline & \multicolumn{3}{|c|}{ Mass of the component (pbw) } \\
\hline \multicolumn{4}{|l|}{ Component A } \\
\hline Rokopol RF 551 & 100 & 75 & 50 \\
\hline Biopolyol L L $0.5 \_150$ & - & 25 & 50 \\
\hline $\mathrm{K}_{12}$ & 1 & 1 & 1 \\
\hline $\mathrm{K}_{\mathrm{Amin}}$ & 1 & 1 & 1 \\
\hline $\mathrm{Sn}(\mathrm{Oct})_{2}$ & 1 & 1 & 1 \\
\hline Silicone SR-393 & 1 & 1 & 1 \\
\hline Water & 1 & 1 & 1 \\
\hline$n$-pentane & 1 & 1 & 1 \\
\hline \multicolumn{4}{|l|}{ Component B } \\
\hline pMDI & 205.8 & 241.3 & 250 \\
\hline
\end{tabular}

$$
\mathrm{HV}=\frac{(B-A) \cdot M \cdot 56.1}{w}
$$

where $A$ is the volume of $0.5 \mathrm{M}$ sodium hydroxide solution required for the titration of a sample $(\mathrm{mL}), B$ is the volume of sodium hydroxide solution required for the titration of the blank solution ( $\mathrm{mL}), M$ is the molarity of sodium hydroxide solution, and $w$ is the amount of the sample (g) to be analyzed.

The determination of biomass conversion degree was performed as follows: A 1-g sample of organic polyol was diluted 20 times with ethanol and stirred with a magnetic stirrer for $4 \mathrm{~h}$. Next, the sample was filtered under vacuum and the isolated solids were washed with ethanol. The solid fraction was dried at $105{ }^{\circ} \mathrm{C}$ to constant weight. The degree of conversion was calculated according to the following formula:

$$
\% \text { Biomass }_{\text {conversion ratio }}=100-\frac{\left(\frac{W_{1}-W_{2}}{W_{3}}\right) \cdot W_{4} \cdot 100}{W_{5}}
$$

where $W_{1}$ is the total dry weight of filtering crucible with biomass residue; $W_{2}$ is the net weight of filtering crucible without biomass residue; $W_{3}$ is the weight of biopolyols weighted for biomass conversion analysis; $W_{4}$ is the total weight of biopolyols obtained via liquefaction; and $W_{5}$ is the weight of biomass added during liquefaction.

The viscosity of biopolyols was determined according to ASTM D 4878-08 using an $\mathrm{R} / \mathrm{S}$ portable viscometer, equipped with a small sample adapter, temperature probe and temperature control unit. The viscosity was determined at $25 \pm 0.5{ }^{\circ} \mathrm{C}$ using rotational speeds recommended in the standard. 
Sol fraction was determined during swelling test. Samples of PU/PIR foams (around $0.2 \mathrm{~g}$ ) were swollen in xylene for $72 \mathrm{~h}$ (room temperature). Sol fraction was calculated as mass difference of biocomposites before swelling $\left(W_{1}\right)$ and after extraction $\left(W_{2}\right)$, according to Eq. (3)

$$
\text { Sol fraction }=\frac{W_{1}-W_{2}}{W_{1}} \times 100 \%
$$

FTIR spectrophotometric analysis was performed to determine the structure of the bio-based polyol. The analysis was performed at a resolution of $4 \mathrm{~cm}^{-1}$ using a Nicolet 8700 apparatus (Thermo Electron Corporation) equipped with a snap-Gold State II, which allows for making measurements in the reflection configuration mode.

Oxidation onset temperature (OOT) test was used to evaluate the effectiveness of antioxidants in biopolyols. The tests were performed under oxygen atmosphere using a NETSCH DSC F3 differential scanning calorimeter. The oxygen flow was maintained at $20 \mathrm{~mL} / \mathrm{min}$. The biopolyol samples (12 mg each) were placed in open aluminum pans and heated from 35 to $250{ }^{\circ} \mathrm{C}$, at a heating rate of $10{ }^{\circ} \mathrm{C} / \mathrm{min}$. All the experiments were performed at least in duplicate. The OOT values were calculated by using NETZSCH Proteus Thermal Analysis software.

The water content of the produced biopolyols was assessed by using Karl-Fischer titration. The samples were diluted with methanol and titrated with Fischer reagent. The measurements of biopolyol density were performed at $25{ }^{\circ} \mathrm{C}$ by means of a pycnometer. The $\mathrm{pH}$ values were measured with a VOLTCRAFT $\mathrm{pH}-100$ ATC $\mathrm{pH}$ meter at $25^{\circ} \mathrm{C}$.

\section{Characterization of polyurethanes}

The apparent density of polyurethane samples was calculated in accordance with PN-EN ISO 845:2000, as the ratio of the sample weight to the sample volume. The volume of the samples having a cubic shape was measured with a slide caliper, with an accuracy of $0.1 \mathrm{~mm}$. The samples were weighed using an electronic analytical balance, with an accuracy of $0.1 \mathrm{mg}$.

The compression strength of the PU samples was estimated in accordance with PN-EN ISO 604:2006. The cube-shaped samples with the dimensions of $50 \times 50 \times 50 \mathrm{~mm}^{3}$ were measured with a slide caliper, with an accuracy of $0.1 \mathrm{~mm}$. The compression test was performed on a Zwick/Roell tensile tester at a constant speed of $10 \mathrm{~mm} / \mathrm{min}$ to $40 \%$ deformation.

The thermogravimetric analysis (TGA) was performed on a NETZSCH TG 209 apparatus using 5-mg samples within the temperature range $100-600{ }^{\circ} \mathrm{C}$ in nitrogen atmosphere, at a heating rate of $15^{\circ} \mathrm{C} / \mathrm{min}$.

The cell morphology of polyurethane samples was investigated with a PhilipsFEI XL 30 environmental scanning electron microscope (ESEM) using an acceleration of $25 \mathrm{kV}$. The samples were cut at room temperature, while the observations were performed in wet mode. 


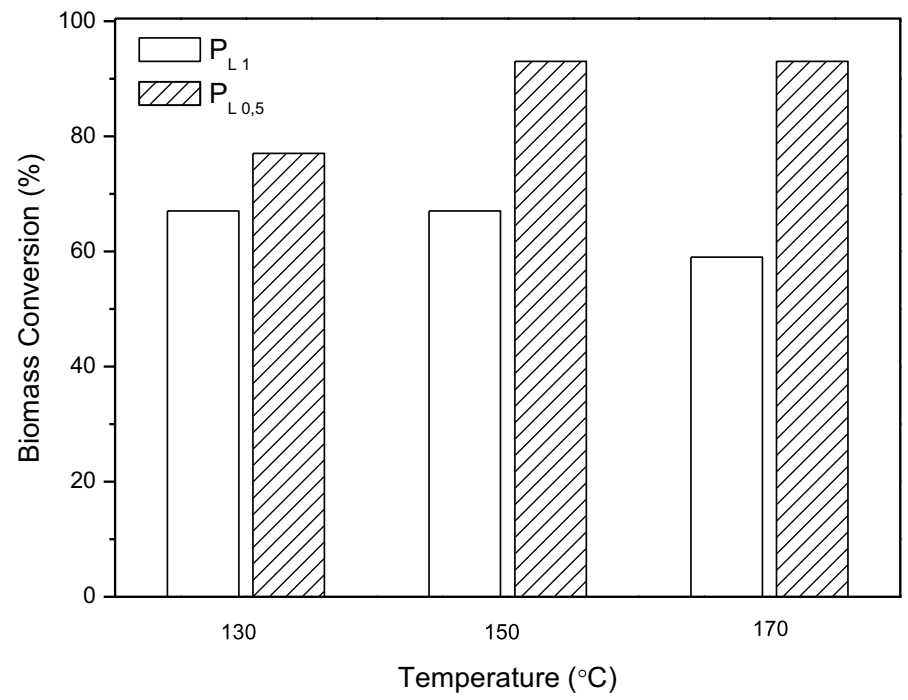

Fig. 1 Effects of reaction temperature on the biomass conversion for different reaction temperatures

Table 2 Physical properties of biopolyols obtained via microwave-assisted liquefaction of lignin

\begin{tabular}{lllllll}
\hline Property & \multicolumn{7}{l}{ Sample } & & & \\
\cline { 2 - 6 } & $\mathrm{L}_{0.5 \_130}$ & $\mathrm{~L}_{0.5 \_150}$ & $\mathrm{~L}_{0.5 \_170}$ & $\mathrm{~L}_{1 \_130}$ & $\mathrm{~L}_{1 \_150}$ & $\mathrm{~L}_{1 \_170}$ \\
\hline $\begin{array}{l}\text { Hydroxyl value } \\
(\mathrm{mg} \mathrm{KOH} / \mathrm{g})\end{array}$ & 622 & 611 & 617 & 653 & 670 & 668 \\
$\begin{array}{l}\text { Density }\left(\mathrm{g} / \mathrm{cm}^{3}\right) \\
\text { Water content }(\mathrm{wt} \%)\end{array}$ & 0.48 & 0.45 & 0.39 & 0.50 & 0.44 & 0.33 \\
pH value & 6.40 & 6.45 & 6.50 & 6.30 & 6.35 & 6.40 \\
OOT $\left({ }^{\circ} \mathrm{C}\right)$ & 162.9 & 156.6 & 148.1 & 173.3 & 170.6 & 166.8 \\
\hline
\end{tabular}

\section{Results and discussion}

\section{Characterizations of bio-based polyol}

In the presented studies, liquefaction of lignin was carried out at three different temperatures. The influence of reaction temperature on biomass conversion for the two lignin to solvent ratios is presented in Fig. 1 and Table 2.

During liquefaction process, the reactions of alcoholysis and hydrolysis take place, which cause a decrease in hydroxyl value (Yip et al. 2009). The initial HV of $\mathrm{L}_{1}$ system equaled $805 \mathrm{mg} \mathrm{KOH} / \mathrm{g}$, while for $\mathrm{L}_{0.5}$ it was $1048 \mathrm{mg} \mathrm{KOH} / \mathrm{g}$. A reduction in the hydroxyl value was observed, which indicates a liquefaction reaction. The hydroxyl value of $\mathrm{L}_{0.5}$ system was higher than that of $\mathrm{L}_{1}$, which resulted from the larger number of reactive $-\mathrm{OH}$ groups per sample volume of $\mathrm{L}_{0.5}$ polyol. It can be 
seen that $\mathrm{HV}$ is not significantly affected by temperature as it ranges from 610 to $670 \mathrm{mg} \mathrm{KOH} / \mathrm{g}$.

The application of glycerol in large excess, which was used as a solvent for liquefaction, may cause its condensation resulting in the generation of polyglycerol. As mentioned before, during liquefaction, hydrolysis of biomass takes place, and therefore water, which is the by-product of glycerol condensation, is responsible for the breakdown of the long molecules of biomass. The shorter chains are more reactive, and thus, the reaction yield increases. For the systems containing a lower amount of lignin, the biomass conversion increases with increasing temperature, which indicates that the liquefaction process has occurred. In the case of systems containing higher amounts of lignin, the biomass conversion decreases with increasing temperature, which shows that the condensation processes dominate over liquefaction. The addition of $\sim 30 \%$ of lignin to the system results in increased viscosity, which limits the liquefaction process and shifts the balance between two competing processes toward condensation of solvents. Based on a literature review, the most frequently used amount of biomass for the liquefaction process is $5-30 \%$ ( $\mathrm{Hu}$ et al. 2012b; Cinelli et al. 2013).

The values of density, water content, $\mathrm{pH}$ and oxidation onset time of biopolyols obtained via microwave-assisted liquefaction of lignin are listed in Table 2. It was determined that the reaction temperature and percentage content of biomass do not significantly affect the density and $\mathrm{pH}$ of the obtained polyols. The water content of biopolyols decreased with increasing reaction temperature. By comparing biopolyols obtained at the same temperature but with a higher biomass-to-solvent ratio, a water content drop of $15 \%$ can be observed for $170{ }^{\circ} \mathrm{C}$ systems. The liquefaction process was conducted in a microwave reactor where the water molecules with high dipole moment $(1.84 \mu)$ vibrate due to the applied magnetic field (Steinfeld et al. 1999). The processes of condensation and liquefaction lead to the formation of water as a by-product, which can either participate in the decomposition of biomass particles or evaporate due to high temperature.

The oxidation onset temperature of biopolyol in the system containing more biomass is higher compared to low-lignin systems. This is probably due to the fact that the products formed in the systems containing higher amounts of biomass mainly originate from the condensation of solvents, the latter being characterized by the higher values of OOT than those of the liquefaction products. This finding has been confirmed by the outcome of the analysis of hydroxyl numbers and biomass conversion values.

Based on the presented results of polyols' analysis, sample $\mathrm{L}_{0.5}$ obtained at $150{ }^{\circ} \mathrm{C}$ was used for further manufacturing of rigid polyurethane foams. Selected polyol was characterized by the hydroxyl value of $670 \mathrm{mg} \mathrm{KOH} / \mathrm{g}$, viscosity of $3.30 \mathrm{~Pa}$ s and obtained at $93 \%$ yield of microwave-assisted liquefaction of lignin.

The viscosity values, flow curves and fitted mathematical models were derived on the basis of rheological measurements.

Figure $2 \mathrm{a}, \mathrm{b}$ shows the flow curves of polyols prepared at different temperatures during the lignin liquefaction. The flow curves have a nonlinear character; therefore, the analyzed liquids can be classified as non-Newtonian fluids (Dziubiński et al. 

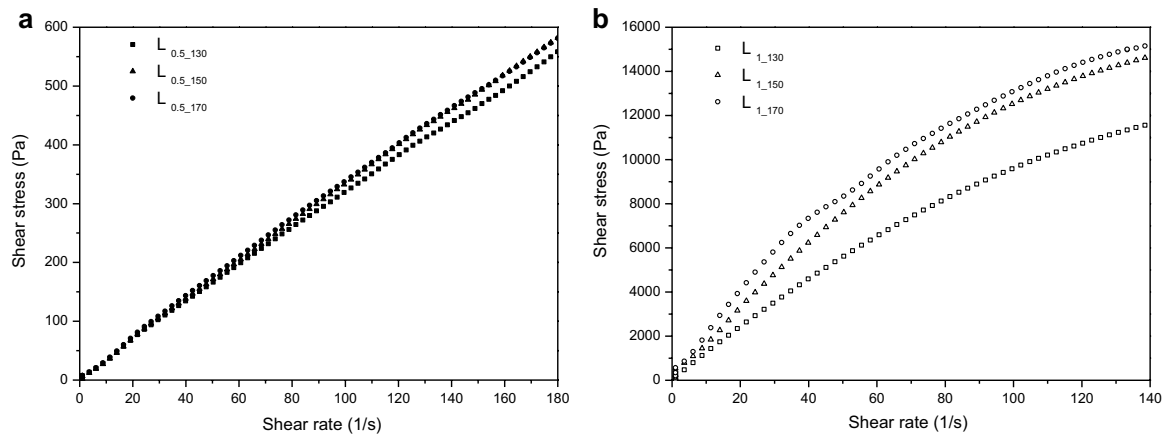

Fig. 2 Flow curves of biopolyols $\mathrm{L}_{0.5}$ (a) and $\mathrm{L}_{1}$ (b) obtained at various temperatures

2009). The slope of the flow curve is closely connected to the fluid's viscosity, as confirmed by the equation below (Schramm 2000).

$$
\tan \alpha=\eta_{0}
$$

In the case of samples containing higher amounts of biomass, a significant increase in tangent $\alpha$ was observed, which is an indication of the higher viscosity of the analyzed biopolyols. For the two samples containing the same amount of biomass, an increase in $\tan \alpha$ with increasing reaction temperature was also noticed.

The relationship between the biopolyol viscosity and shear rate is illustrated in Fig. 3. It can be seen that viscosity decreases with increasing shear rate, which is characteristic for shear-thinning (pseudoplastic) fluids (Björn et al. 2012). As the

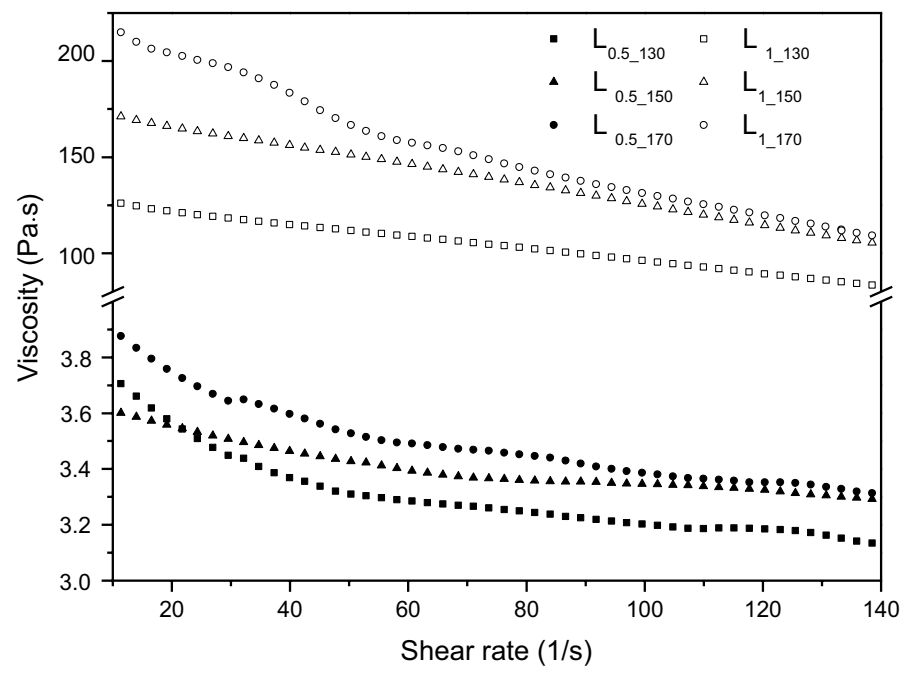

Fig. 3 Effect of biomass content on the biopolyol viscosity 
shear rate increases, the asymmetrical particles gradually become ordered along the direction of the flow. The apparent viscosity decreases until the particles lined up along the direction of the flow cannot be any closer and the flow curve becomes a line (Kosmela et al. 2016). The increase in viscosity with reaction temperature was observed for both lignin contents. As mentioned before, condensation of solvent occurs during the liquefaction process, suggesting the generation of higher molecular weight products, hence the increase in viscosity.

Fitting of the Ostwald-de Waele and Herschel-Bulkley models to the obtained results of rheological measurements is presented in Table 3. The mathematical models approximate the real behavior of non-Newtonian fluids. The Ostwald-de Waele model is based on the following formulas $(5,6)$ :

$$
\begin{gathered}
\tau=K\left(\frac{\partial u}{\partial y}\right)^{n} \\
\mu_{\text {eff }}=K\left(\frac{\partial u}{\partial y}\right)^{n-1}
\end{gathered}
$$

where $K$ is the flow consistency index, $\partial u / \partial y$ is the shear rate perpendicular to the plane of shear, $n$ is the flow behavior index, and $\mu_{\text {eff }}$ represents an effective viscosity as a function of shear rate.

Table 3 Ostwald-de Waele and Herschel-Bulkley linear functions based on the rheological data from

\begin{tabular}{|c|c|c|c|c|c|}
\hline Sample code & Function & & $K\left(\mathrm{~Pa} \mathrm{~s}^{n}\right)$ & $n(-)$ & $R^{2}$ \\
\hline \multicolumn{6}{|c|}{ Ostwald-de Waele linear functions } \\
\hline $\mathrm{L}_{0.5 \_130}$ & $y=4.12 \cdot x^{0.9447}$ & & 4.126 & 0.9447 & 0.9999 \\
\hline $\mathrm{L}_{0.5 \_150}$ & $y=3.75 \cdot x^{0.9741}$ & & 3.756 & 0.9741 & 0.9998 \\
\hline $\mathrm{L}_{0.5 \_170}$ & $y=4.38 \cdot x^{0.9432}$ & & 4.387 & 0.9432 & 0.9999 \\
\hline $\mathrm{L}_{1 \_130}$ & $y=143.31 \cdot x^{0.9085}$ & & 143.312 & 0.9085 & 0.9877 \\
\hline $\mathrm{L}_{1 \_150}$ & $y=194.25 \cdot x^{0.9079}$ & & 194.257 & 0.9079 & 0.9859 \\
\hline $\mathrm{L}_{1 \_170}$ & $y=254.84 \cdot x^{0.8715}$ & & 254.841 & 0.8715 & 0.9867 \\
\hline Sample code & Function & $\tau_{0}(\mathrm{~Pa})$ & $\mu_{\mathrm{om}}\left(\mathrm{Pa} \mathrm{s}^{n}\right)$ & $n(-)$ & $R^{2}$ \\
\hline \multicolumn{6}{|c|}{ Herschel-Bulkley linear functions } \\
\hline $\mathrm{L}_{0.5 \_130}$ & $y=4.24 \cdot x^{0.9381}$ & 0 & 4.245 & 0.9381 & 0.9997 \\
\hline $\mathrm{L}_{0.5 \_150}$ & $y=4.12 \cdot x^{0.9073}$ & 0 & 4.127 & 0.9073 & 0.9996 \\
\hline $\mathrm{L}_{0.5 \_170}$ & $y=4.75 \cdot x^{0.9257}$ & 0 & 4.751 & 0.9257 & 0.9997 \\
\hline $\mathrm{L}_{1 \_130}$ & $y=352.76 \cdot x^{0.708}$ & 0 & 352.765 & 0.708 & 0.9937 \\
\hline $\mathrm{L}_{1 \_150}$ & $y=488.39 \cdot x^{0.6965}$ & 0 & 488.391 & 0.6965 & 0.9922 \\
\hline $\mathrm{L}_{1 \_170}$ & $y=599.67 \cdot x^{0.6682}$ & 0 & 599.674 & 0.6682 & 0.9953 \\
\hline
\end{tabular}
bio-based polyol samples 
Fluids can be categorized into three groups based on their flow behavior indices, i.e., pseudoplastic fluids for $n<1$; non-Newtonian fluids for $n=1$; and dilatant fluids for $n>1$. All the analyzed biopolyols were characterized by $n<1$, which confirmed their pseudoplastic character.

The Herschel-Bulkley model is based on the following constitutive Eq. (7):

$$
\tau=\tau_{0}+K \dot{\gamma}^{n}
$$

where $\tau$ is the shear stress, $\tau_{0}$ is yield stress, $\dot{\gamma}$ is shear rate, $K$ is the flow consistency index, and $n$ is the flow behavior index.

In the case of the Herschel-Bulkley model, the yield stress is a significant parameter. It determines the amount of stress that has to be delivered to the fluid to make it flow. The biomass that has not reacted and is still present in the analyzed system can result in an increase in the yield stress. For all the analyzed systems, $\tau_{0}$ equaled 0 , which indicates that the obtained biopolyols started to flow immediately after the force had been applied.

In the study, the Ostwald-de Waele and the Herschel-Bulkley models were applied to describe polyols with $15 \%$ content of lignin $\left(\mathrm{L}_{0.5}\right)$, due to the small differences in the $R^{2}$ value. For larger contents of lignin in the analyzed systems, the Herschel-Bulkley model was a more suitable choice.

The FTIR spectra of the reagents (lignin, glycerol and 1,4-butanediol) used in biomass liquefaction as well as the reaction product, a biopolyol obtained at $150{ }^{\circ} \mathrm{C}$, are shown in Fig. 4. The relatively large peak at $3300 \mathrm{~cm}^{-1}$ corresponds to the stretching vibrations of hydroxyl groups, associated also with moisture present in the polyol (Deng and Ting 2005). The signals in the $2940-2870 \mathrm{~cm}^{-1}$ region were attributed to the stretching of $\mathrm{CH}_{3}, \mathrm{CH}_{2}$ and $\mathrm{CH}$ aliphatic groups (Collier et al. 1997). The bands present at 1600 and $1510 \mathrm{~cm}^{-1}$ were assigned to the skeletal vibrations

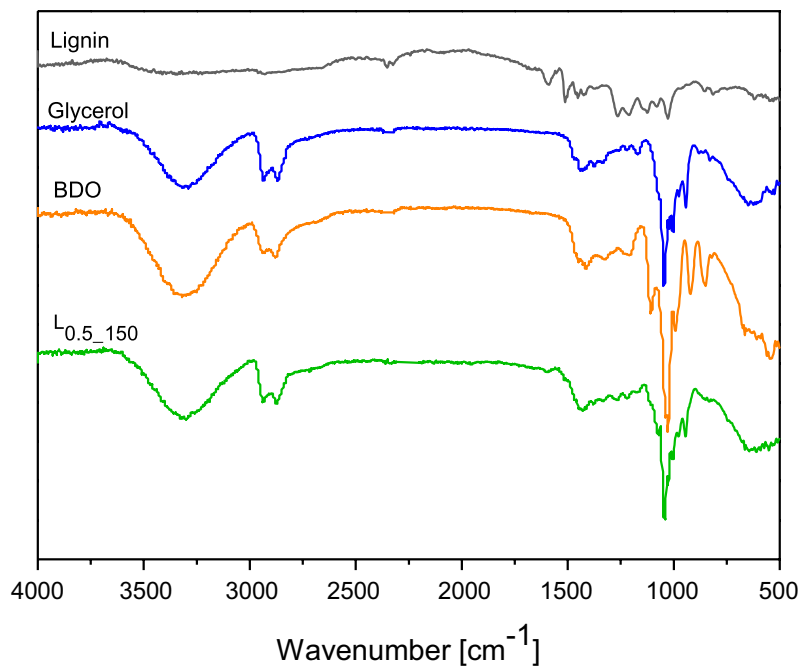

Fig. 4 FTIR spectra of lignin, glycerol, 1,4-butanediol and biopolyol $P_{\text {L0.5_150 }}$ 
of the benzene ring originating from lignin (Jin et al. 2011). Absorption bands at $1450-1415 \mathrm{~cm}^{-1}$ region can be associated with the $\mathrm{CH}_{2}$ and HOC in-plane bending vibrations. On the other hand, the stretching vibrations associated with the $\mathrm{C}-\mathrm{O}$ and $\mathrm{C}=\mathrm{O}$ groups were observed at $1220 \mathrm{~cm}^{-1}$ (Schwanninger et al. 2004). The bands characteristic for $\mathrm{C}-\mathrm{O}-\mathrm{C}$ ether groups were found in the range of $1050-1000 \mathrm{~cm}^{-1}$; their intensity suggests that the obtained polyol may actually be a polyether (Gottwald and Watcher 1997; Grube et al. 2006; Cai et al. 2007). The peak observed at $940 \mathrm{~cm}^{-1}$ resulted from the $\mathrm{C}=\mathrm{C}$ or $\mathrm{C}-\mathrm{H}$ out-of-plane vibrations originating from aromatic rings of the lignin used (Faix 1991).

\section{Mechanical and thermal properties of analyzed polyurethanes}

Apparent density is a very important parameter which determines the mechanical and thermal properties of PU foams. The values of apparent density, the share of sol fraction and compressive strength of the obtained polyurethane foams are shown in Table 4.

The presented results show that there is a close relationship between the bulk density of porous materials and their mechanical properties (Poudel and Oh 2012). The replacement of petroleum-based polyol by bio-based polyol $\mathrm{L}_{0.5 \_150}$ resulted in the lowered volumetric expansion of the reaction mixture during polymerization. Hence, higher content of bio-based polyol $\mathrm{L}_{0.5 \_150}$ in the formulation caused an increase in the apparent density of rigid PU foams compared to the reference foam, which led to their increased compressive strength. Similar effects connected to the application of bio-based polyol were reported by other authors (Tan et al. 2011). Figure 5 shows compression stress-strain curves of rigid polyurethane foams. The addition of biopolyol to the foam formulation caused an increase in Young's modulus which indicates a higher rigidity of the obtained foams. The maximum value of compressive strength for foams with biopolyol compared to the reference foam is shifted to lower strain which is a sign of the greater brittleness of the materials obtained. For this reason, the values in Table 4 are given for $20 \%$ strain. The use of 25 and $50 \mathrm{wt} \%$ of bio-based polyol $\mathrm{L}_{0.5 \_150}$ instead of Rokopol RF 551 increased the apparent density by 19.3 and $80.7 \%$, respectively. The values of compressive stress follow the same pattern as the values of apparent density in the produced foams. In the case of foams containing 25 and $50 \mathrm{wt} \%$ of biopolyol, the compressive stress increased by 12.0 and $36.4 \%$, respectively. The share of sol fraction in rigid PU foams decreased with increasing content of biopolyol, which suggests the higher cross-linking density of the produced material (Yang et al. 2012).

Table 4 Comparison of the properties of rigid polyurethane foams

\begin{tabular}{lccc}
\hline Property & \multicolumn{3}{l}{ Sample } \\
\cline { 2 - 4 } & $P_{0}$ & $P_{25}$ & $P_{50}$ \\
\hline Density $\left(\mathrm{kg} / \mathrm{m}^{3}\right)$ & $83 \pm 3$ & $99 \pm 4$ & $150 \pm 8$ \\
Compressive strength $(\mathrm{kPa})$ & $627 \pm 12$ & $703 \pm 11$ & $855 \pm 14$ \\
Share of sol fraction $(\mathrm{wt} \%)$ & $4.8 \pm 0.4$ & $4.2 \pm 0.2$ & $3.0 \pm 0.5$ \\
\hline
\end{tabular}




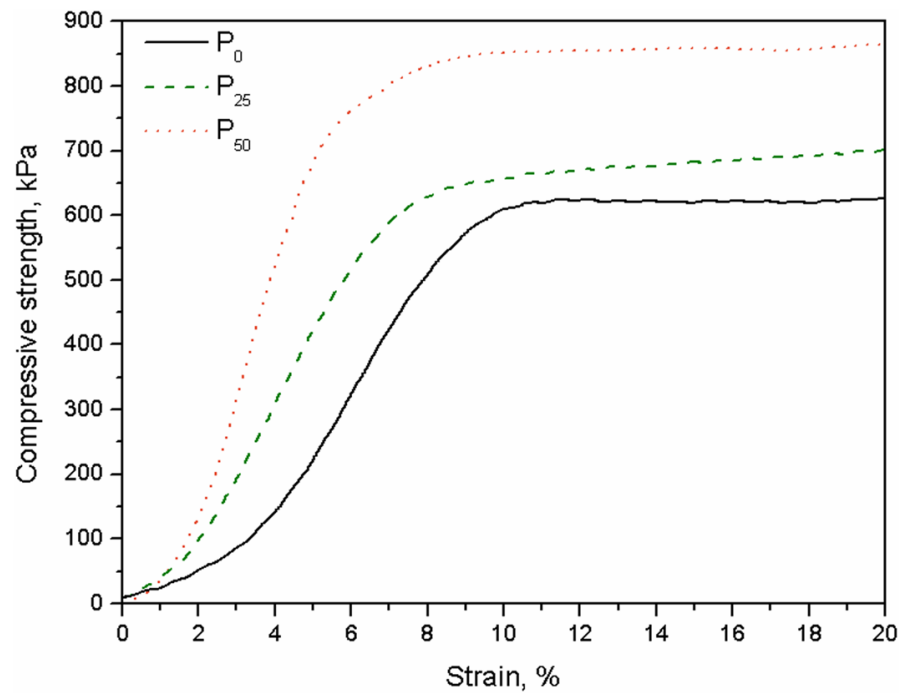

Fig. 5 Compression stress-strain curves of rigid polyurethane foams

In general, the physical properties of foams are not only dependent on the rigidity of the polymer matrix, but are also related to the morphology of the foam cell. Thus, it is necessary to analyze the cellular structure of the porous materials. Figure $6 \mathrm{a}-\mathrm{c}$ shows the SEM images of the reference material and bio-based polyurethane foam. The application of 25 and $50 \mathrm{wt} \%$ of biopolyol in the foam formulations resulted in a decrease in cell size by 33 and $68 \mu \mathrm{m}$, respectively. The pore surface of neat PU was mostly regular and smooth. However, the cellular structure was closely related to the content of lignin in the PU matrix. Due to the incorporation of bio-based polyol, the cellular shape became more inhomogeneous and less regular. This was probably because the biopolyol with lignin did not disperse well in the PU foam (Xue et al. 2014). Table 5 shows other parameters describing the cellular structure of the analyzed materials that have been calculated on the basis of microscopic images in Fig. 6. The parameters were estimated from the following equations:

$$
\begin{gathered}
\mathrm{AR}=\frac{L_{l}}{L_{s}} \\
R=4 \cdot \frac{A}{\pi \cdot L_{l}^{2}}
\end{gathered}
$$

where $L_{1}$ and $L_{s}$ are the respective lengths of the major and minor axes of an ellipse, and $A$ stands for the square area of the ellipse.

The values of aspect ratio (AR) and roundness $(R)$ for perfectly round pores in rigid polyurethane foams equal 1. It was observed that the application of 25 and $50 \mathrm{wt} \%$ of biopolyols to PU foam systems did not significantly affect the cellular 

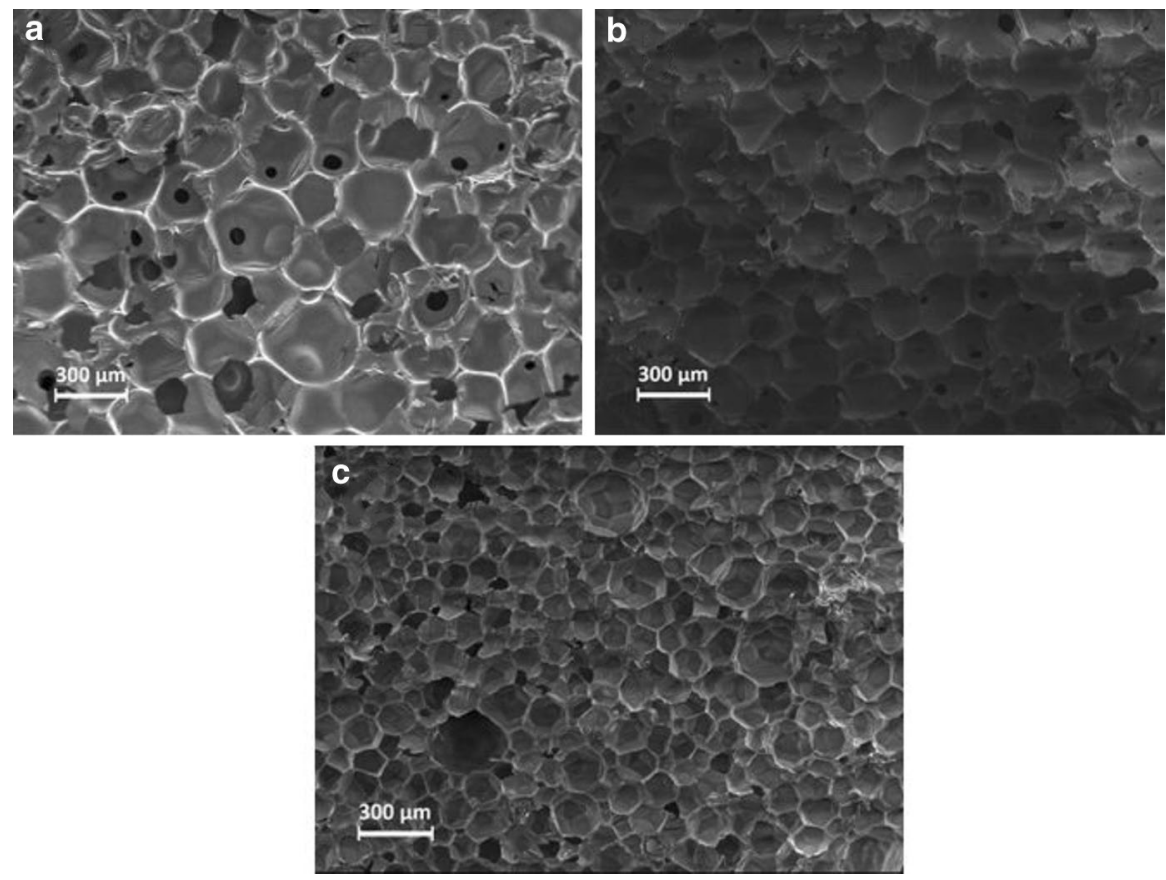

Fig. 6 SEM images of PU foams coded a $P_{0}$, b $P_{25}$ and $\mathbf{c} P_{50}$

Table 5 Parameters describing the cellular structure of the obtained materials

\begin{tabular}{llll}
\hline Property & \multicolumn{2}{l}{ Sample } & \\
\cline { 2 - 4 } & $P_{0}$ & $P_{25}$ & $P_{50}$ \\
\hline Cell size $(\mu \mathrm{m})$ & $236 \pm 18$ & $203 \pm 15$ & $168 \pm 20$ \\
Aspect ratio & $1.5 \pm 0.3$ & $1.6 \pm 0.5$ & $1.5 \pm 0.3$ \\
Roundness & $0.7 \pm 0.2$ & $0.7 \pm 0.2$ & $0.8 \pm 0.1$ \\
\hline
\end{tabular}

shape (AR of ca. 1.5 and $R=0.7$ for all samples). This finding points to the uniform evaporation of blowing agent during the foaming process.

Thermal stability of different materials is commonly determined via thermogravimetric analysis in a nitrogen atmosphere. The results of TGA are presented in Fig. 7 and Table 6. The initial degradation temperatures of rigid polyurethane foams, corresponding to a $2 \%$ mass loss, fell within a range of $247-258{ }^{\circ} \mathrm{C}$. Depending on the type of isocyanates and polyols used, urethane bonds break down in the aforementioned temperature range (Lee et al. 2002). The replacement of 25 and $50 \mathrm{wt} \%$ of petroleum-based polyol by biopolyol resulted in an increase in $T_{5 \%}$ by 6 and $13{ }^{\circ} \mathrm{C}$, respectively. The increased thermal stability was probably due to higher crosslinking density. The mixture of biopolyols in rigid polyurethane foams caused the shift of the peaks corresponding to the degradation of rigid segments $\left(T_{\max }\right)$ toward higher temperatures. 

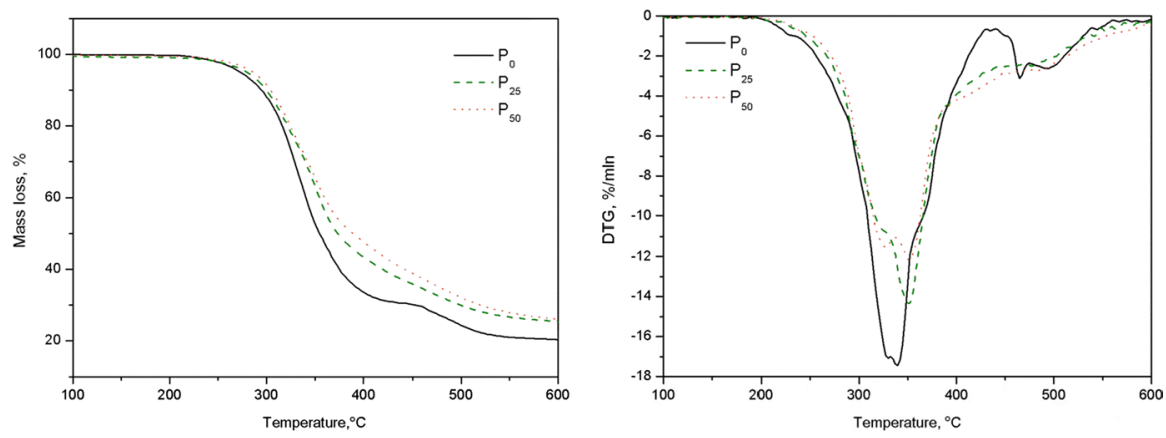

Fig. 7 Effect of biopolyol admixture on the mass loss (left) and differential thermogravimetric curves (right) as a function of temperature for rigid polyurethane foams

Table 6 Characteristics of thermal degradation in rigid polyurethane foams

\begin{tabular}{llllll}
\hline Sample & \multicolumn{2}{l}{ Mass loss $(\%)$} & $T_{\max }\left({ }^{\circ} \mathrm{C}\right)$ \\
\cline { 2 - 5 } & 2 & 5 & 10 & 50 & \\
& \multicolumn{2}{l}{ Temperature $\left({ }^{\circ} \mathrm{C}\right)$} & & & \\
\hline$P_{0}$ & 247.7 & 273.5 & 294.9 & 354.8 & 339.1 \\
$P_{25}$ & 248.0 & 279.6 & 299.6 & 373.4 & 351.2 \\
$P_{50}$ & 258.3 & 286.2 & 304.1 & 389.5 & 351.4 \\
\hline
\end{tabular}

\section{Conclusion}

Microwave liquefaction was employed to liquefy a lignin using crude glycerol and 1,4-butanediol. The biopolyols were a synthesis at three temperatures and two ratios of lignin to 1,4-butanediol to crude glycerol. Lignin-based products were characterized by hydroxyl number, biomass conversion, rheological properties, structure (FTIR analysis), water content, density and resistance to oxidation (OOT). The results showed that biopolyol $\mathrm{L}_{0.5}$, containing $15 \%$ of lignin and produced at a temperature of $150{ }^{\circ} \mathrm{C}$, has the optimal parameters $(\mathrm{LOH}=670 \mathrm{mg} \mathrm{KOH} / \mathrm{g} ; C=93 \%$; $\mu=3.30 \mathrm{~Pa} \mathrm{~s}$ ) which make it suitable for the use in the production of rigid polyurethane foams. Bio-based polyurethane foams were received by partial replacement of petrochemical polyol by biopolyol in the amount of 25 and $50 \mathrm{wt} \%$. It was found that the biopolyol admixture caused an increase in apparent density, compressive strength and thermal stability of the obtained foams. This study suggests that liquefaction of lignin using crude glycerol and 1,4-butanediol is a promising alternative to petroleum-based materials, and the application of microwave heating significantly shortens the reaction time, which has a positive effect on the costs of the final product. 
Open Access This article is distributed under the terms of the Creative Commons Attribution 4.0 International License (http://creativecommons.org/licenses/by/4.0/), which permits unrestricted use, distribution, and reproduction in any medium, provided you give appropriate credit to the original author(s) and the source, provide a link to the Creative Commons license, and indicate if changes were made.

\section{References}

Abdel Hakim AA, Nassar M, Emam A, Sultan M (2011) Preparation and characterization of rigid polyurethane foam prepared from sugar-cane bagasse polyol. Mater Chem Phys 129:301-307. https://doi. org/10.1016/j.matchemphys.2011.04.008

Agrawal D (2006) Microwave sintering, brazing and melting of metallic materials. Non-Ferrous Mater Extr Process 4:183-192. https://doi.org/10.1080/0371750X.2006.11012292

Alma MH, Basturk MA, Digrak M (2003) New polyurethane-type rigid foams from liquified wood powders. J Mater Sci Lett 22:1225-1228. https://doi.org/10.1023/A:1025356702660

Behrendt F, Neubauer Y, Oevermann M et al (2008) Direct liquefaction of biomass. Chem Eng Technol 31:667-677. https://doi.org/10.1002/ceat.200800077

Björn A, Segura de La Monja P, Karlsson A, Ejlertsson J, Svensson BH (2012) Rheological characterization. Biogas, Dr. Sunil Kumar (Ed.), InTech, ISBN 978-953-51-0204-5

Cai Z, Gao J, Li X, Xiang B (2007) Synthesis and characterization of symmetrical benzodifuranone compounds with femtosecond time-resolved degenerate four-wave mixing technique. Opt Commun 272:503-508. https://doi.org/10.1016/j.optcom.2006.11.056

Chen F, Lu Z (2009) Liquefaction of wheat straw and preparation of rigid polyurethane foam from the liquefaction products. J Appl Polym Sci 111:508-516. https://doi.org/10.1002/app.29107

Cinelli P, Anguillesi I, Lazzeri A (2013) Green synthesis of flexible polyurethane foams from liquefied lignin. Eur Polym J 49:1174-1184. https://doi.org/10.1016/j.eurpolymj.2013.04.005

Clark DE, Folz DC, West JK (2000) Processing materials with microwave energy. Mater Sci Eng A 287:153-158. https://doi.org/10.1016/S0921-5093(00)00768-1

Collier W, Kalasinsky V, Schultz T (1997) Infrared study of lignin: assignment of methoxyl C-H bending and stretching bands. Holzforschung 51:167-168. https://doi.org/10.1515/hfsg.1997.51.2.167

de la Hoz A, Diaz-Ortiz A, Moreno A (2005) Microwaves in organic synthesis. Thermal and non-thermal microwave effects. Chem Soc Rev 34:164-178. https://doi.org/10.1039/b411438h

Deng S, Ting Y-P (2005) Characterization of PEI-modified biomass and biosorption of $\mathrm{Cu}(\mathrm{II}), \mathrm{Pb}$ (II) and Ni(II). Water Res 39:2167-2177. https://doi.org/10.1016/j.watres.2005.03.033

Dziubiński M, Kiljański T, Sek J (2009) Podstawy reologii i reometrii płynów (Fundamentals of rheology and rheometry). Lodz Unversity of Technology Publisher, Lodz (in Polish)

Faix O (1991) Classification of lignins from different botanical origins by FT-IR spectroscopy. Holzforschung 45:21-28. https://doi.org/10.1515/hfsg.1991.45.s1.21

Gandini A, Belgacem MN (2008) Lignins as components of macromolecular materials. In: Gandini A, Belgacem MN (eds) Monomers, polymers and composites from renewable resources. Elsevier, pp 243-271

Gao LL, Liu YH, Lei H et al (2010) Preparation of semirigid polyurethane foam with liquefied bamboo residues. J Appl Polym Sci 116:1694-1699. https://doi.org/10.1002/app.31556

Gottwald W, Watcher G (1997) IR-Spektroskopie für Anwender. Wiley-VCH, Weinheim

Grube M, Lin JG, Lee PH, Kokorevicha S (2006) Evaluation of sewage sludge-based compost by FT-IR spectroscopy. Geoderma 130:324-333. https://doi.org/10.1016/j.geoderma.2005.02.005

Hassan E, Barbary M, Shukry N (2008) Polyhydric alcohol liquefaction of some lignocellulosic agricultural residues. Ind Crops Prod 27:33-38. https://doi.org/10.1016/j.indcrop.2007.07.004

Hatakeyama H, Hatakeyama T (2005) Environmentally compatible hybrid-type polyurethane foams containing saccharide and lignin components. Macromol Symp 224:219-226. https://doi.org/10.1002/ masy.200550619

Hu S, Li Y (2014) Polyols and polyurethane foams from acid-catalyzed biomass liquefaction by crude glycerol: effects of crude glycerol impurities. J Appl Polym Sci 131:9054-9062. https://doi. org/10.1002/app.40739

Hu S, Luo X, Wan C, Li Y (2012a) Characterization of crude glycerol from biodiesel plants. J Agric Food Chem 60:5915-5921. https://doi.org/10.1021/jf3008629 
Hu S, Wan C, Li Y (2012b) Production and characterization of biopolyols and polyurethane foams from crude glycerol based liquefaction of soybean straw. Bioresour Technol 103:227-233. https://doi. org/10.1016/j.biortech.2011.09.125

Jin Y, Ruan X, Cheng X, Lü Q (2011) Liquefaction of lignin by polyethyleneglycol and glycerol. Bioresour Technol 102:3581-3583. https://doi.org/10.1016/j.biortech.2010.10.050

Kosmela P, Hejna A, Formela K et al (2016) Biopolyols obtained via crude glycerol-based liquefaction of cellulose: their structural, rheological and thermal characterization. Cellulose 23:2929-2942. https ://doi.org/10.1007/s10570-016-1034-7

Kunaver M, Jasiukaityte E, Čuk N, Guthrie JT (2010) Liquefaction of wood, synthesis and characterization of liquefied wood polyester derivatives. J Appl Polym Sci 115:1265-1271. https://doi. org/10.1002/app.31277

Kurimoto Y, Takeda M, Koizumi A et al (2000) Mechanical properties of polyurethane films prepared from liquefied wood with polymeric MDI. Bioresour Technol 74:151-157. https://doi.org/10.1016/ S0960-8524(00)00009-2

Lee WJ, Lin MS (2008) Preparation and application of polyurethane adhesives made from polyhydric alcohol liquefied taiwan acacia and china fir. J Appl Polym Sci 109:23-31. https://doi.org/10.1002/ app. 28007

Lee S-H, Yoshioka M, Shiraishi N (2000) Liquefaction of corn bran (CB) in the presence of alcohols and preparation of polyurethane foam from its liquefied polyol. J Appl Polym Sci 78:319-325. https:// doi.org/10.1002/1097-4628(20001010)78:2<319::AID-APP120>3.0.CO;2-Z

Lee SH, Teramoto Y, Shiraishi N (2002) Biodegradable polyurethane foam from liquefied waste paper and its thermal stability, biodegradability, and genotoxicity. J Appl Polym Sci 83:1482-1489. https ://doi.org/10.1002/app.10039

Leonelli C, Veronesi P, Denti L et al (2008) Microwave assisted sintering of green metal parts. J Mater Process Technol 205:489-496. https://doi.org/10.1016/j.jmatprotec.2007.11.263

Liang L, Mao Z, Li Y et al (2006) Liquefaction of crop residues for polyol. BioResources 1:1-9

Luo X, Hu S, Zhang X, Li Y (2013) Thermochemical conversion of crude glycerol to biopolyols for the production of polyurethane foams. Bioresour Technol 139:323-329. https://doi.org/10.1016/j.biort ech.2013.04.011

Mazo P, Estenoz D, Sponton M, Rios L (2012) Kinetics of the transesterification of castor oil with maleic anhydride using conventional and microwave heating. J Am Oil Chem Soc 89:1355-1361. https:// doi.org/10.1007/s11746-012-2020-3

Menezes RR, Souto PM, Kiminami RHGA (2007) Microwave hybrid fast sintering of porcelain bodies. J Mater Process Technol 190:223-229. https://doi.org/10.1016/j.jmatprotec.2007.02.041

Poudel J, Oh SC (2012) Degradation characteristics of wood using supercritical alcohols. Energies 5:5038-5052. https://doi.org/10.3390/en5125038

Schramm G (2000) A practical approach to rheology and rheometry, 2nd edn. Gebrueder HAAKE $\mathrm{GmbH}$, Karlsruhe, pp 18-19

Schwanninger M, Rodrigues JC, Pereira H, Hinterstoisser B (2004) Effects of short-time vibratory ball milling on the shape of FT-IR spectra of wood and cellulose. Vib Spectrosc 36:23-40. https://doi. org/10.1016/j.vibspec.2004.02.003

Sequeiros A, Serrano L, Briones R, Labidi J (2013) Lignin liquefaction under microwave heating. J Appl Polym Sci 130:3292-3298. https://doi.org/10.1002/app.39577

Steinfeld JI, Francisco JS, Hase WL (1999) Chemical kinetics and dynamics, 2nd edn. Prentice Hall, Englewood Cliffs

Tan S, Abraham T, Ference D, Macosko CW (2011) Rigid polyurethane foams from a soybean oil-based polyol. Polymer (Guildf) 52:2840-2846. https://doi.org/10.1016/j.polymer.2011.04.040

Wang H, Chen HZ (2007) A novel method of utilizing the biomass resource: rapid liquefaction of wheat straw and preparation of biodegradable polyurethane foam (PUF). J Chin Inst Chem Eng 38:95-102. https://doi.org/10.1016/j.jcice.2006.10.004

Wang T, Zhang L, Li D et al (2008) Mechanical properties of polyurethane foams prepared from liquefied corn stover with PAPI. Bioresour Technol 99:2265-2268. https://doi.org/10.1016/j.biort ech.2007.05.003

Xue B-L, Wen J-L, Sun R-C (2014) Lignin-based rigid polyurethane foam reinforced with pulp fiber: synthesis and characterization. ACS Sustain Chem Eng 2:1474-1480. https://doi.org/10.1021/sc500 1226 
Xue BL, Wen JL, Sun RC (2015) Producing lignin-based polyols through microwave-assisted liquefaction for rigid polyurethane foam production. Materials (Basel) 8:586-599. https://doi.org/10.3390/ ma8020586

Yadoji P, Peelamedu R, Agrawal D, Roy R (2003) Microwave sintering of Ni-Zn ferrites: comparison with conventional sintering. Mater Sci Eng B Solid State Mater Adv Technol 98:269-278. https:// doi.org/10.1016/S0921-5107(03)00063-1

Yamada T, Ono H (1999) Rapid liquefaction of lignocellulosic waste by using ethylene carbonate. Bioresour Technol 70:61-67. https://doi.org/10.1016/S0960-8524(99)00008-5

Yan Y, Pang H, Yang X et al (2008) Preparation and characterization of water-blown polyurethane foams from liquefied cornstalk polyol. J Appl Polym Sci 110:1099-1111. https://doi.org/10.1002/ app. 28692

Yan Y, Hu M, Wang Z (2010) Kinetic study on the liquefaction of cornstalk in polyhydric alcohols. Ind Crops Prod 32:349-352. https://doi.org/10.1016/j.indcrop.2010.05.015

Yang L-T, Zhao C-S, Dai C-L et al (2012) Thermal and mechanical properties of polyurethane rigid foam based on epoxidized soybean oil. J Polym Environ 20:230-236. https://doi.org/10.1007/s1092 4-011-0381-6

Yip J, Chen M, Szeto YS, Yan S (2009) Comparative study of liquefaction process and liquefied products from bamboo using different organic solvents. Bioresour Technol 100:6674-6678. https://doi. org/10.1016/j.biortech.2009.07.045 